\title{
Finite Element Analysis of Mechanical Performance of Concrete-filled Steel Tube Composite Frame under Different Fire Time
}

\author{
*Yucheng $\mathrm{LI}^{1}$, Yongming $\mathrm{SHAO}^{2}$, Xing $\mathrm{WANG}^{3}$ \\ 1,2,3 (School of mechanical engineering, anhui sanlian university, hefei 230601, China)
}

\begin{abstract}
Research on the mechanical properties of concrete-filled steel tube composite frames at high temperatures is one of the current hot issues. In this paper, the finite element simulation software is used to analyze the concrete-filled steel tube composite frame, introduce the failure mode of the concrete-filled steel tube composite frame under high temperature, and deeply study the simulation results of the single-story mechanical performance. The single-span concrete-filled steel tube composite frame structure based on the analysis of the concrete-filled steel tube bearing capacity, including the role of each beam and column in different temperature fields, structural fields and coupling fields, as well as the role in the entire section. As the temperature increases and decreases, its mechanical properties will change significantly under the action of concentrated loads. The bearing capacity of the composite frame at high temperature is somewhat lower than that at room temperature. The research results can provide a reference for the reinforcement and repair of the steel tube concrete composite frame under high temperature.
\end{abstract}

\section{Introduction}

Steel tube concrete composite frame is widely used in contemporary architecture[1]. At the same time, with the increase in building types, new building materials and technologies have emerged, thus accelerating the development of modern architecture. However, with the frequent occurrence of fires, the fire resistance of the concrete-filled steel tube composite frame is poor. Experts [2-4] also realized the importance of concrete-filled steel tube composite frames in the study of fire resistance. Therefore, they invested a lot of time and money in the research of concrete-filled steel tube composite frames. The framework has been researched [5-8]. At present, there are few studies on the bearing capacity of concrete-filled steel tube composite frames under high temperature. The failure mode, structural field and coupling field of the composite frame structure under high temperature, the changes in the mechanical properties of beams and columns under high temperature, and the comparative analysis of the bearing capacity of the CFST composite frame under full span are introduced. The cross-section fire state has reference value for the further study of the concrete-filled steel tube composite frame under high temperature.

\section{Failure mode of concrete filled steel tubular composite frame}

\subsection{Failure mode}

The bearing capacity of concrete-filled steel tubular composite frame structure is better at room temperature, and can resist various external loads. However, under high temperature, the material is affected by temperature, and the overall resistance to external load is weakened. Under the coupling field, the composite frame under external load continuously forms plastic hinge until the structure forms mechanism and damages.

\subsection{Temperature rise curve}

The most widely used in my country is the ISO834 standard heating curve developed by the International Standards Organization, as shown in the following formula:

$$
\mathrm{T}-\mathrm{T}_{0}=345 \lg (8 \mathrm{t}+1)
$$

Where:

$T$-Corresponds totThe average indoor air temperature at all times;

$T_{0} \longrightarrow$ Take $20^{\circ} \mathrm{C}$

$t$-Time of exposure to fire. 
The standard temperature rise curve is used to study the bearing capacity effect at high temperature.

\section{Numerical calculation of bearing capacity of CFST composite frame under high temperature}

\subsection{Model conditions}

Conditions: The single-story single-span concrete-filled steel tube composite frame structure has a length of $6 \mathrm{~m}$ and a height of $4 \mathrm{~m}$. The thermal-mechanical coupling analysis of the composite frame is carried out, and the flexural deformation performance of the concrete-filled steel tube composite frame is obtained.

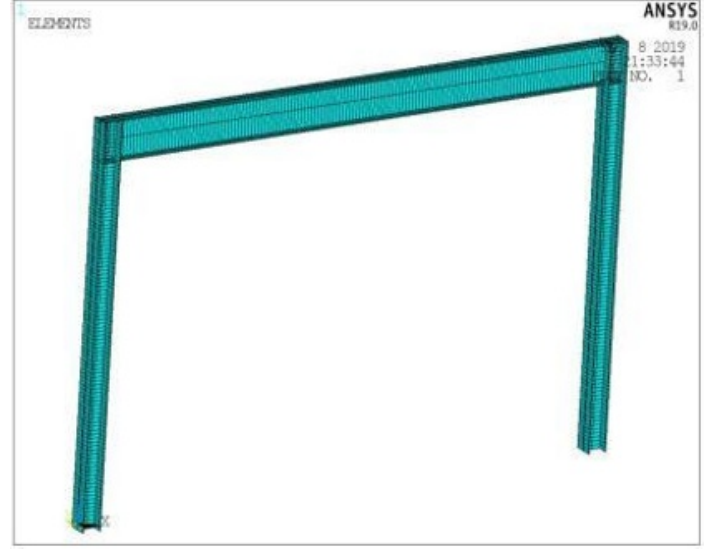

Figure 1. Computational model of combined framework

\subsection{Model analysis}

Through numerical simulation analysis, the temperature curve diagram of the combined frame under different fire time is obtained.

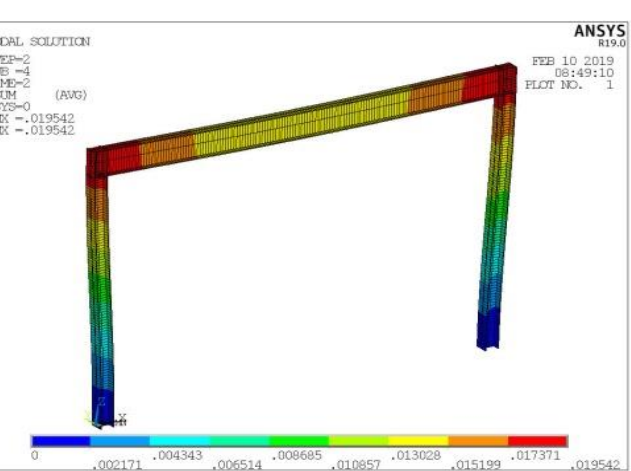

(a) $300 \mathrm{~s}$

(b) $600 \mathrm{~s}$

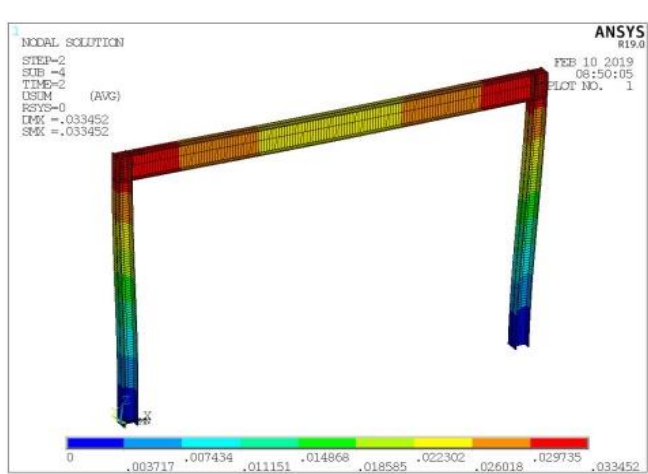

(c) $6000 \mathrm{~s}$

(d) $7200 \mathrm{~s}$

Figure 2. Temperature distribution diagram of the outer concrete of the concrete-filled steel tube composite frame under working condition a different fire time

With the temperature rising, the bearing capacity of composite frame decreases with the temperature rising, and the mechanical properties change obviously at the concentrated load. The failure load and ultimate bending moment of the composite frame under high temperature are reduced to a certain extent compared with that under normal temperature, and the redistribution is more obvious at the key joint points, and finally the mechanism is formed and damaged,The load-bearing capacity of the second case is smaller than that of the first case, which indicates that the bearing capacity of the two-story and two-span CFST composite frame is better under full section fire.

\section{4 conclusion}

This paper analyzes the finite element simulation results of the mechanical properties of the single-story single-span composite frame under high temperature. 
(1) This paper analyzes the failure mode of the bearing capacity of the concrete-filled steel tube composite frame structure under high temperature, and draws the conclusion that the mechanical properties of the concrete-filled steel tube composite frame change greatly under high temperature.

(2) Numerical simulation of the mechanical properties of the concrete-filled steel tube composite frame under high temperature. With the increase of temperature, the failure load, ultimate bending moment and mechanical properties of the single-story and single-span concrete-filled steel tube composite frame have undergone major changes.

\section{Acknowledgment}

Fund projects: Natural science research projects in Anhui Universities (KJ2020A0805), academic support project of top academic talents of anhui universities (gxbjZD56).

About the author: li yucheng (1994 -), male, born in suzhou, anhui province, master's degree, teaching assistant, mainly engaged in research on fire performance theory and safety assessment of steel structure, Email:947080764@qq.com.

\section{References}

1. Cai Xinhua. research on underpinning technology of housing structure [D]. Shanghai: Tongji university, 2007. (Cai Xinhua. research on underpinning technology of housing structure [d]. Shanghai: Tongji university, 2007.)

2. Jiang Yuansheng. Some experiences on reinforcement method of reinforced concrete structure with enlarged cross section $[\mathrm{J}]$. Anhui
Jianzhu University, 2008(02):115-116.(Jiang Yuansheng. Experiences of Reinforcing Reinforced Concrete Structures by Increasing Section [J]. Anhui University Architecture, 2008 (02): 115-116)

3. Ding Rui, Liu Haowu, Hou Jing, Shen Guoqing. Research on Nondestructive Testing Technology of concrete filled steel tubular arch bridge [J]. Piezoelectric and acousto optic, 2004, (06): 447-450

4. Jing Yatao. Study on fire resistance of concrete filled steel tubular frame with special-shaped columns [D]. South China University of technology, 2009

5. Wang Jin. Study on fire resistance of eccentrically loaded thin walled concrete filled steel tubular columns [D]. Huaqiao University, 2009

6. Feng Chengyuan, Li Guoqiang, Jiang Binhui. Study on the influence of steel high temperature material property model on the collapse simulation of concrete filled steel tubular composite frame structure under fire $[\mathrm{J}]$. Engineering mechanics, 2019,36 (12): 24-36 + 78

7. Li Guoqiang, Han Linhai, Lou Guobiao, Jiang Shouchao. Fire resistance design of steel structures and steel-concrete composite structures [M]. Beijing: China Construction Industry Press, 2006, 5

8. $\mathrm{Xu}$ Lei, Yao Xiong Liang. Analysis of factors affecting the fire resistance of square steel tube reinforced concrete columns and Study on practical calculation method $[\mathrm{J}]$. Industrial building, 2006, (11): 37-41 